\title{
Controle do mofo-preto do cajueiro com indutores de resistência
}

\author{
Wéverson Lima Fonseca ${ }^{1}$, Francisco Marto Pinto Viana ${ }^{2}$, Marcio Akio Ootani ${ }^{3}$, José Emilson Cardoso ${ }^{2} @$, \\ Rita de Cassia Alves Pereira ${ }^{2}$, Marlon Vagner Valentim Martins ${ }^{2}$
}

\begin{abstract}
${ }^{1}$ Departamento de Fitotecnia, Universidade Federal do Ceará, CEP 60356-001, Fortaleza, Ceará, Brasil. ${ }^{2}$ Laboratório de Fitopatologia, Embrapa Agroindústria Tropical, CEP 60511-110, Fortaleza, Ceará, Brasil. ${ }^{3}$ Laboratório de Bioprocessos, Centro de Tecnologias Estratégicas do Nordeste, CEP 50740-540, Recife, Pernambuco, Brasil.
\end{abstract}

Autor para correspondência: Wéverson Lima Fonseca (weverson.limaf@gmail.com)

Data de chegada: 09/06/2019. Aceito para publicação em: 15/10/2019.

$10.1590 / 0100-5405 / 225015$

O mofo-preto (Pilgeriella anacardii (Bat., J.L. Bezerra, Castr. \& Matta) Arx \& E. Müll.) do cajueiro (Anacardium occidentale L.) causa danos de até $33 \%$ na produção de castanhas em cajueiro-anão (3). A utilização de opções ecologicamente viáveis no controle de doenças de plantas, como os indutores de resistência, tem se mostrado promissora no controle de fitopatógenos. Nesse sentido, objetivou-se comparar o efeito indutor de resistência de produtos químicos e produtos naturais na severidade do mofo-preto do cajueiro.

O estudo foi conduzido no período de abril a novembro de 2017 no Campo Experimental da Embrapa (4'11' 12" S; $38^{\circ} 30^{\prime} 01^{\prime \prime}$ W, e a 79 m de altitude), em Pacajus, Ceará. Em um pomar composto por cajueiro-anão, clone 'CCP 09', as plantas foram submetidas à poda em março visando uniformizar a epidemia. $\mathrm{O}$ experimento foi delineado em blocos ao acaso com quatro repetições de uma planta por parcela, com tratamentos constituídos por: acibenzolar-S-methyl $\left(0,5 \mathrm{~g} \mathrm{~L}^{-1}\right.$, Bion $\left.^{\circledR}\right)$, fosfito de potássio $\left(2 \mathrm{ml} \mathrm{L}^{-1}\right.$, Yantra $\left.{ }^{\circledR}\right)$, ácido salicílico P.A. $\left(1,5 \mathrm{~g} \mathrm{~L}^{-1}\right)$, silício $\left(1 \mathrm{ml} \mathrm{L}^{-1}\right.$, Supra Sílica $\left.{ }^{\circledR}\right)$, uma mistura composta por óleos essenciais de alecrim-pimenta (Lippia sidoides) + capim citronela (Cymbopogon citratus) e a testemunha (sem tratamento). Os óleos essenciais de alecrim-pimenta e citronela foram obtidos por hidrodestilação. A partir de cada óleo essencial, preparou-se $1 \mathrm{~L}$ de emulsão a $0,8 \%$ e aplicada na concentração de $3 \mathrm{~mL}$ de emulsão por litro de água. As aplicações dos tratamentos, efetuadas nas copas (um litro por copa) no período da manhã, iniciaram na floração e repetidas sete vezes a intervalos quinzenais, com pulverizador costal manual de 20 L. As avaliações foram quinzenais durante o ciclo epidêmico, com auxílio de em uma escala descritiva da severidade dos sintomas: $0=$ ausência de sintomas; 1 = área lesionada cobrindo até $2 \%$ da área foliar; 2 = área lesionada cobrindo até 5\% da área foliar; 3 = área lesionada cobrindo de 5 a $25 \%$ da área foliar; e 4 = área lesionada cobrindo mais que $25 \%$ da área foliar (2). Os dados médios de severidade da doença foram integralizados, estimando-se a área abaixo da curva de progresso da doença (AACPD) através da fórmula: AACPD $=\Sigma\left[\left(\mathrm{y}_{1}+\mathrm{y}_{2}\right) / 2\right] *\left(\mathrm{t}_{2}-\mathrm{t}_{1}\right)$, onde $y_{1}$ e $y_{2}$, refere-se a duas avaliações sucessivas da intensidade da doença realizadas nos tempos $\mathrm{t}_{1}$ e $\mathrm{t}_{2}$, respectivamente (1).

Os dados de AACPD foram submetidos à análise de variância utilizando o teste $\mathrm{F}(\mathrm{p}<0,05)$ e as médias comparadas pelo teste Tukey $(p<0,05)$ através do software " $R$ " versão 3.5.1. Para a análise temporal da severidade, foram ajustadas equações de regressão com auxílio do software Sigma Plot 11.0.

A análise estatística das AACPDs referentes aos tratamentos avaliados no controle do mofo-preto do cajueiro, demonstra que houve diferenças significativas entre os tratamentos (Figura 1), com os melhores resultados para a mistura dos óleos de alecrim-pimenta
+ capim citronela, acibenzolar-S-methyl e ácido salicílico, quando comparados à testemunha. Pelas curvas de progresso do mofo-preto do cajueiro, verificou-se também que as notas de severidade da doença nesses tratamentos, foram menores em todo o ciclo epidêmico avaliado. Esta pesquisa ratifica o efeito indutor de resistência de acibenzolar-Smethyl ao mofo-preto do cajueiro, demonstrado em estudo anterior (4), além de relatar dois novos produtos alternativos para o controle da doença: ácido salicílico e a mistura dos óleos de alecrim-pimenta + capim citronela.

Indutores de resistência são eficientes na redução da severidade do mofo-preto em cajueiro anão 'BRS 09'.

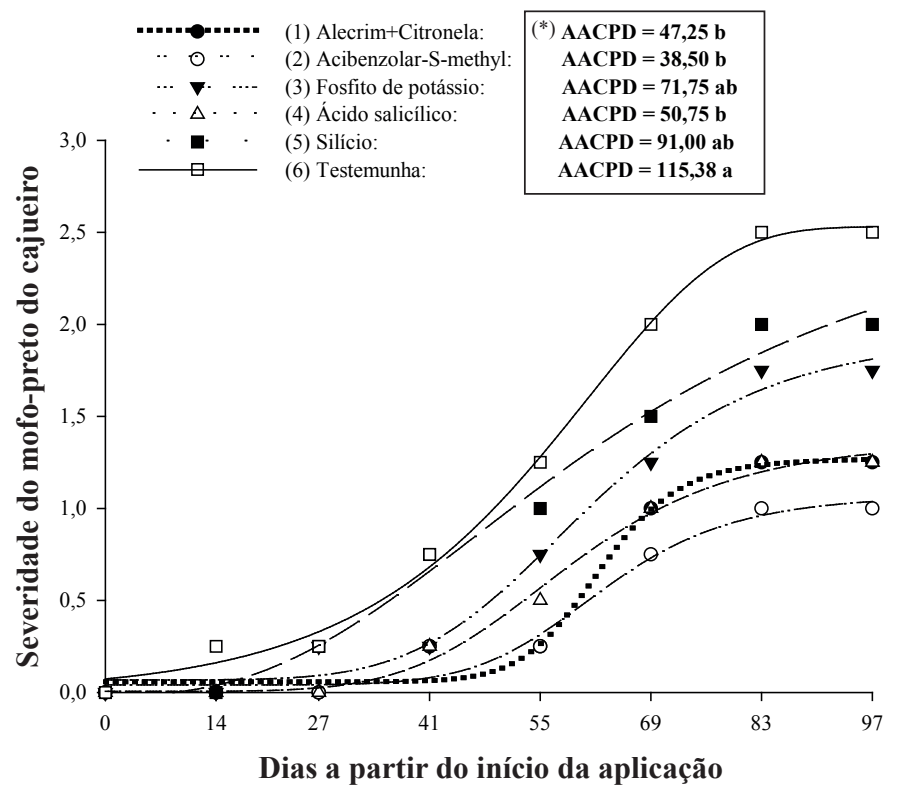

Figura 1. Efeito de indutores de resistência na área abaixo da curva de progresso da doença (AACPD) e curvas de progresso da severidade do mofo-preto do cajueiro.

(*) AACPD: teste de significância da análise de variância: (Probabilidade $>\mathrm{F}$ $=0,0019 ;$ médias seguidas da mesma letra não diferem pelo Teste de Tukey a $5 \%$ de significância.

(1) $\mathbf{Y}=\mathbf{0 , 0 5 8 0}+\mathbf{1 , 2 1 2 8} /\left(\mathbf{1}+\mathbf{a b s}(\mathbf{x} / \mathbf{6 2 , 4 9 5 8})^{-\mathbf{1 2 , 3 9 8 2}}\right) \quad\left(\mathrm{R}^{2}=0,97\right) \quad \operatorname{Pr}>\mathrm{F}=0,0008$

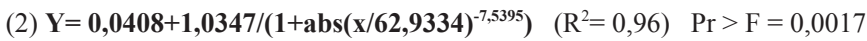

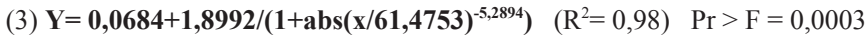

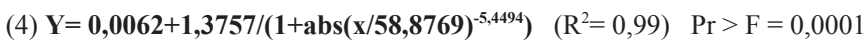

(5) $\left.\mathbf{Y}=\mathbf{- 0 , 0 1 5 4 + 2 , 8 2 0 0 / ( 1 + a b s ( x / 6 4 , 1 9 4 3})^{-2,5839}\right) \quad\left(R^{2}=0,98\right) \quad \operatorname{Pr}>F=0,000$

(6) $\mathrm{Y}=\mathbf{i f}\left(\mathbf{x}<=\mathbf{5 4 , 7 1 1 6 - 1 2 8 9 5 0 , 6 6 7 8} * \ln (\mathbf{2})^{(\mathbf{1} / 7448,2862)}\left(\mathrm{R}^{2}=0,99\right) \quad \mathrm{Pr}>\mathrm{F}=0,0001\right.$ 


\section{REFERÊNCIAS}

1. Campbell, C.L.; Madden, L.V. Introduction to plant disease epidemiology. New York: John Wiley, 1990. 532p.

2. Cardoso, J.E.; Santos, A.A.; Freire, F.C.O.; Viana, F.M.P.; Vidal, J.C.; Oliveira, J.N.; Uchoa, C.N. Monitoramento de doenças na cultura do cajueiro. Fortaleza: Embrapa Agroindústria Tropical, 2006. 24p. (Documentos, 47).
3. Viana, F.M.P.; Cardoso, J.E.; Martins, M.V.V.; Freire, F.C.O. Doenças do cajueiro. Informe Agropecuário, Belo Horizonte, v.37, n.290, p.34-46, 2016.

4. Viana, F.M.P.; Lima, J.S.; Lima, F.A.; Cardoso, J.E. Control of cashew black mould by acibenzolar-S-methyl. Tropical Plant Pathology, Brasília, DF, v.37, n.5, p.354-357, 2012. 